\title{
Perceptions and knowledge of oncology patients of covid-19 infection in a developing country
}

Arwa Y Alami ( $\square$ aalalami@khcc.jo )

King Hussein Cancer center

\section{Gadeer Abdeen}

King Hussein Cancer center

\section{Rula El Sabbagh}

King Hussein Cancer center

Amneh Dabor

King Hussein Cancer center

\section{Research Article}

Keywords: Covid-19, cancer, knowledge, patients, virtual clinics, oncology

Posted Date: June 11th, 2020

DOI: https://doi.org/10.21203/rs.3.rs-34530/v1

License: (c) (1) This work is licensed under a Creative Commons Attribution 4.0 International License. Read Full License 


\section{Abstract}

\section{Purpose}

To assess knowledge, beliefs, and measures followed by oncology patients in a developing country during the pandemic covid-10.

\section{Methods}

A survey conducted by phone calls to a group of patients treated at a cancer hospital, answers were recorded by the investigators. Data were analysed descriptively.

Results

Two hundred and one oncology patients answered the survey, mean age was 51.49 years; $66.2 \%$ were females, $49.2 \%$ of them were on active anticancer treatment. All patients knew of covid-19, $91 \%$ believed that it was contagious but only $46.3 \%$ thought they could become infected. While $75.1 \%$ believed that coming to the hospital increased the risk of infection, only 33.3\% preferred to postpone their treatment. Only a minority thought that they will not seek medical treatment if they were infected with covid- 19 . Most of the participants followed preventive measures such as hand washing and use of disinfectants. Patients were followed by phone calls instead of clinical visits and $85.6 \%$ were satisfied with it.

Conclusion:

Study showed that most oncology patients are aware of the covid-19 pandemic, methods of spread and risk of infection. Most of them followed protective measures and adhered to social distancing. Patients were satisfied with phone calls as a replacement to clinical visits during the pandemic and their treatment plan was followed.

\section{Introduction}

Coronaviruses are a large family of viruses that can cause disorders ranging from a mild cold to severe diseases. In December 2019, a novel coronavirus called severe acute respiratory syndrome coronavirus 2 (SARSCoV-2) caused an outbreak of COVID-19. Typical symptoms of

COVID-19 include fever, cough, shortness of breath, and muscle pain. Severe complications have been reported to occur in $33 \%$ of patients with COVID-19 and include acute respiratory distress syndrome, acute renal failure, acute respiratory injury, septic shock, and severe pneumonia. Currently, there is no specific treatment or approved vaccine against it [1].

As of 30 March 2020, a total of 638,146 cases and 30,039 confirmed deaths have been reported across $>150$ countries [2]. The cancer community currently faces many difficult questions [2]. 
Jordan reported the first case of COVID-19 in second of March 2020, and in 20/3/2020 the country announced total lockdown in an attempt to control the spread of the disease. The lockdown affected all facilities including the hospitals which were directed to treat only emergency cases. Cancer treatment was considered elective and surgeries were postponed and al 1 outpatients' clinics were closed.

At King Hussein Cancer Centre (KHCC), several measures were taken to ensure safety of cancer patients, all outpatients' clinics were cancelled and screening areas were set to examine patients for covid-19 before entering the hospital. In addition, clinical appointments were done through telephone calls by the consultants and clinical coordinators to ensure patients are being followed. Medications were sent to patients to their homes, and all radiology follow up exams were postponed to minimise contact between patients.

Health literacy has emerged over the past 3 decades as one of the strongest psychosocial determinants of health, and it has also been shown to explain a range of health disparities by age, race/ethnicity, and socioeconomic status [5]. Thus, in uncertain times like this, when the interpretation of critical and everchanging public health messages is paramount, many vulnerable populations may be further marginalized by inadequate health communication, posing substantial risks to themselves and their communities [6].

The aim of the study was to determine the current awareness of COVID-19 among a vulnerable group( oncology patients) in a developing country with a strict total lockdown, and their perception of the seriousness of its threat, their concern related to contracting the virus, measures taken to prevent infection, and its effect on their treatment plan.

\section{Methods}

The study was based on a survey prepared by the investigators and conducted through phone calls. The final version of the survey was pilot tested on a random sample of 20 participants in order to ensure the appropriate number of questions, clarity of scientific vocabulary and the possibility of adding or omitting questions based on their performance. The questionnaire was originally written in Arabic language, as the majority of the public would have difficulties in comprehending the English version. The participants were adult patients who have outpatient appointments at KHCC, and all patients included in this telephone survey had provided consent. Data were collected from 15 through 30 April 2020. The phone call took ten minutes, Participant responses were recorded by interviewers. No compensation was given to participants.

The questionnaire collected basic demographic data on age, sex, diagnosis, education level, area of residence. The survey consisted of many questions concerning knowledge about covid-19, risk of infection in oncology patients, attitudes and practices to avoid infection, hospital visits and benefits gained from virtual appointments instead of the conventional outpatients' appointments. The Institutional Review Board at KHCC approved present study. 


\section{Statistical analysis}

Descriptive statistics were calculated for all patient characteristics and survey responses. Data was analyzed using SPSS-16, frequency analysis was done for all variables data presented in frequency and percentages. Correlation between different categorical groups was measured by calculating chi-square test, $p$ value of less than 0.05 was considered significant.

\section{Results}

In total, 201 oncology adult patients were enrolled in the study, 230 were contacted, of these, 20 declined participation and 10 could not be reached. Overall cooperation rate was $87.4 \%$. Of them there were $66.2 \%$ females and $33.8 \%$ males. The age range was between 18-89 years, and the median age was 51.49 years. Of the total number $49.2 \%$ were on active treatment and $50.8 \%$ were on follow up. Most of the participants lived in the central part of the country $77.6 \%$, and $48.8 \%$ had a high school level of education. Personal characteristics are shown in Table 1.

Table 1

\begin{tabular}{|c|c|c|c|}
\hline & & Frequency & percentage \\
\hline \multirow[t]{2}{*}{ Gender } & Male & 68 & $33.8 \%$ \\
\hline & Female & 133 & $66.2 \%$ \\
\hline \multirow[t]{5}{*}{ Educational level } & High School & 98 & $48.8 \%$ \\
\hline & Diploma & 44 & $21.9 \%$ \\
\hline & University & 50 & $24.9 \%$ \\
\hline & Higher education & 9 & $4.5 \%$ \\
\hline & High School & 98 & $48.8 \%$ \\
\hline \multirow[t]{3}{*}{ Living area } & North & 32 & $15.9 \%$ \\
\hline & Central & 156 & $77.6 \%$ \\
\hline & South & 13 & $6.5 \%$ \\
\hline \multirow[t]{4}{*}{ Year of diagnosis } & Before 2005 & 8 & $4.3 \%$ \\
\hline & 2005- 2010 & 17 & $9.2 \%$ \\
\hline & $2011-2015$ & 26 & $14.1 \%$ \\
\hline & $2016-2020$ & 133 & $72.3 \%$ \\
\hline \multirow[t]{2}{*}{ Diagnosis } & Solid tumours & 162 & $86.2 \%$ \\
\hline & Haematological tumours & 26 & $13.8 \%$ \\
\hline \multirow[t]{2}{*}{ On treatment/ follow-up } & On Treatment & 94 & $49.2 \%$ \\
\hline & Follow up & 97 & $50.8 \%$ \\
\hline
\end{tabular}

personal characteristics of participants

All participants had heard of the coronavirus (COVID-19), and almost all believed that it is contagious (91\%). Of them $46.3 \%$ believed that they could be infected. Only $62.7 \%$ thought that the virus is 
transmitted through air droplets while $29.4 \%$ thought that it is transferred through blood. The majority knew that it can be transmitted through physical contact $96.5 \%$.

Eighty -three \% believed that they are more prone to get infected and $76.1 \%$ believed that they have a higher risk to develop complications. Many thought that chemotherapy increased the risk of infection $64.7 \%$, and $59.7 \%$ thought that after completing their treatment the risk of infection will decrease.

Participants were asked about what measure they took to avoid infection; $46.3 \%$ stayed at home, while those who went out of the house was mostly to the hospital. $85.6 \%$ of them wore gloves when they went of the house, and $86.1 \%$ wore face masks, $91.5 \%$ took off their shoes outside the house on their return. $97 \%$ avoided handshake and $100 \%$ washed their hands frequently during the day. $88.1 \%$ used disinfectants, and $96 \%$ practiced social distancing.

Participants were asked about their knowledge of corona infection, $94.5 \%$ knew the symptoms of infection with COVID-19 and 92\% knew how to get help if they suspected they were infected. Only $26.9 \%$ thought that they would not seek medical opinion if they got infected. Table 2

Table 2 
Knowledge of Corona infection:

1. Do you know about the corona virus

you believe it is contagious

3. Do you believe you might get infected

4. Do you think there is a vaccine for it

5. Do you believe it is transmitted through blood

6. Do you believe it is Transmitted through air droplets

7. Do you believe it is Transmitted through contact

\begin{tabular}{|l|l|l|}
\hline Yes & No & I do not know \\
\hline $\begin{array}{l}200 \\
(99.5 \%)\end{array}$ & $1(0.5 \%)$ \\
\hline $183(91 \%)$ & $9,(4.5 \%)$ & $9,(4.5 \%)$ \\
\hline $\begin{array}{l}93, \\
(46.3 \%)\end{array}$ & $32,(15.9 \%)$ & $76,(37.8 \%)$ \\
\hline $\begin{array}{l}44, \\
(21.9 \%)\end{array}$ & $86,(42.8 \%)$ & $71,(35.3 \%)$ \\
\hline $\begin{array}{l}59, \\
(29.4 \%)\end{array}$ & $91,(45.3 \%)$ & $51,(25.4 \%)$ \\
$\begin{array}{l}126, \\
(62.7 \%)\end{array}$ & $48,(23.9 \%)$ & $27,(13.4 \%)$ \\
$\begin{array}{l}164, \\
(96.5 \%)\end{array}$ & $4,(2 \%)$ & $3,(1.5 \%)$ \\
\hline
\end{tabular}

Risk of infection

1. Do you believe cancer patients are at higher risk of getting covid-19

2. Are you at higher risk of developing complications if infected

3. Do you believe active chemotherapy will increase risk of infection

4. Do you believe RXT increases risk of infection

5. Do you believe surgery increases risk of infection

6. Do you believe that if you are off treatment then the risk of infection is low

Infection prevention

Do you go out of the house

1. How many times per week

2. Do you wear gloves when you go out

3. Do you wear face masks

4. Do you change your clothes when you get home

5. Do you leave your shoes outside upon your return

6. Do you take a shower when you get home

7. o you wash your hands frequently

8. Do you use disinfectants

9. Do you avoid handshaking

10. Do you do social distancing

11. Did the hospital provide you with instructions on how to protect yourself

\begin{tabular}{|l|l|l|}
\hline $\begin{array}{l}167, \\
(83.0 \%)\end{array}$ & $17,(8.5 \%)$ & $17,(8.5 \%)$ \\
\hline $\begin{array}{l}153, \\
(76.1 \%)\end{array}$ & $22,(10.9 \%)$ & $26,(12.9 \%)$ \\
\hline $\begin{array}{l}130, \\
(64.7 \%)\end{array}$ & $20,(10 \%)$ & $51 .(25.4 \%)$ \\
\hline $\begin{array}{l}62, \\
(30.8 \%)\end{array}$ & $46,(22.9 \%)$ & $93,(46.3 \%)$ \\
\hline $\begin{array}{l}82, \\
(40.8 \%)\end{array}$ & $34,(16.9 \%)$ & $85,(42.3 \%)$ \\
\hline $\begin{array}{l}120, \\
(59.7 \%)\end{array}$ & $54,(26.9 \%)$ & $27,(13.4 \%)$ \\
\hline $\begin{array}{l}108, \\
(53.7 \%)\end{array}$ & $93,(46.3 \%)$ & Was not option for this \\
\hline
\end{tabular}

On average they go out 3 times per week

\begin{tabular}{|l|l|l|}
$\begin{array}{l}172, \\
(85.6 \%)\end{array}$ & $26,(12.9 \%)$ & $3,(1.5 \%)$ \\
\hline $\begin{array}{l}173, \\
(86.1 \%)\end{array}$ & $26,(12.9 \%)$ & $2,(1 \%)$ \\
\hline $\begin{array}{l}174, \\
(86.6 \%)\end{array}$ & $24,(11.9 \%)$ & $3,1.5 \%)$ \\
\hline $\begin{array}{l}184, \\
(91.5 \%)\end{array}$ & $17,(8.5 \%)$ & 0 \\
\hline $\begin{array}{l}120, \\
(59.7 \%)\end{array}$ & $70,(34.8 \%)$ & $11,(5.5 \%)$ \\
\hline $\begin{array}{l}201, \\
(100 \%)\end{array}$ & 0 & 0 \\
\hline $\begin{array}{l}177, \\
(88.1 \%)\end{array}$ & $16,(8 \%)$ & $8,(4 \%)$ \\
\hline $\begin{array}{l}195, \\
(97 \%)\end{array}$ & $5,(2.5 \%)$ & $1,(0.5 \%)$ \\
\hline $\begin{array}{l}193, \\
(96 \%)\end{array}$ & $7,(3.5 \%)$ & $1,(0.5 \%)$ \\
\hline $\begin{array}{l}128, \\
(63.7 \%)\end{array}$ & $61,(3.3 \%)$ & $12,(6 \%)$ \\
\hline
\end{tabular}




\begin{tabular}{|c|c|c|c|}
\hline 1. Do you know the symptoms of corona infection & $\begin{array}{l}190, \\
(94.5 \%)\end{array}$ & $9,(4.5 \%)$ & $2,(1 \%)$ \\
\hline 2. Do you know what to do if you were infected & $\begin{array}{l}185, \\
(92 \%)\end{array}$ & $7,(3.5 \%)$ & $9,(4.5 \%)$ \\
\hline 3. Do you know where to go for testing and treatment & $\begin{array}{l}178, \\
(88.6 \%)\end{array}$ & $12,(6 \%)$ & $11,(5.5 \%)$ \\
\hline $\begin{array}{l}\text { 4. Do you believe that you may not seek medical advice if you suspected that you } \\
\text { got infected. }\end{array}$ & $\begin{array}{l}54, \\
(26.9 \%)\end{array}$ & $\begin{array}{l}140 \\
(69.7 \%)\end{array}$ & $7,(3.5 \%)$ \\
\hline
\end{tabular}

knowledge and prevention of corona virus

The majority $97 \%$ believed that KHCC is taking adequate measures to prevent spread of the disease. Even though $75.1 \%$ believed that coming to the hospital will increase the risk of infection only $33.3 \%$ preferred to postpone their cancer treatment. Patients believed that using their private cars is safer than using ambulance $53.2 \%$.

Patients were followed by phone calls in $82.1 \%$ cases, of these $57.7 \%$ were contacted by their primary physicians and $81.1 \%$ by their clinical coordinators.

Eight five \% thought that their medical questions were addressed and $81.6 \%$ felt that they are being followed medically with a satisfaction rate of $85.6 \%$.

Several actions resulted from the virtual call, $57.2 \%$ of them were given another follow up appointment, $24.9 \%$ were scheduled for chemotherapy, $25.9 \%$ renewed their medication and only $2 \%$ did not understand their treatment plan. Table 3

Table 3 


\begin{tabular}{|c|c|c|c|}
\hline \multicolumn{4}{|l|}{ Hospital appointments: } \\
\hline & Yes & No & I do not know \\
\hline Do you believe the hospital is taking actions to prevent its spread. & 195, $(97 \%)$ & $1,(0.5 \%)$ & $5,(2.5 \%)$ \\
\hline 1. Do you think coming to the hospital might increase risk of infection & $151,(75.1 \%)$ & $38,(18.9 \%)$ & $12,(6 \%)$ \\
\hline 2. Do you prefer to postpone your treatment & 67, $(33.3 \%)$ & $115,(57.2 \%)$ & $19,(9.5 \%)$ \\
\hline 3. Do you think coming to the hospital by ambulance is safer than your own car & $78,(38.8 \%)$ & $107,(53.2 \%)$ & 16, \\
\hline \multicolumn{4}{|l|}{ Outpatients appointments: } \\
\hline 1. Was you contacted by phone concerning your appointment & $165,(82.1 \%)$ & $32,(15.9 \%)$ & $4,(2 \%)$ \\
\hline 2. Were you contacted by your physician or coordinator & $116,(57.7 \%)$ & $78,(38.8 \%)$ & $7,(3.5 \%)$ \\
\hline 3. Were all your questions and concerns answered by the call & $171,(85.1 \%)$ & $21,(10.4 \%)$ & $9,(4.5 \%)$ \\
\hline 4. Did you feel that you are being followed medically & $164,(81.6 \%)$ & $28,(13.9 \%)$ & $9,(4.5 \%)$ \\
\hline 5. Are you satisfied that your treatment plan is followed. & $172,(85.6 \%)$ & $17,(8.5 \%)$ & $12,(6 \%)$ \\
\hline \multicolumn{2}{|l|}{ What actions resulted from the call } & \multicolumn{2}{|c|}{ Frequency } \\
\hline \multicolumn{2}{|l|}{ a. Follow up appointment } & \multicolumn{2}{|l|}{115} \\
\hline \multicolumn{2}{|l|}{ b. Chemotherapy appointment } & \multicolumn{2}{|l|}{50} \\
\hline \multicolumn{2}{|l|}{ c. Surgery appointment } & \multicolumn{2}{|l|}{0} \\
\hline \multicolumn{2}{|l|}{ d. Diagnostic radiology appointment } & \multicolumn{2}{|l|}{30} \\
\hline \multicolumn{2}{|l|}{ e. Radiation oncology appointment } & \multicolumn{2}{|l|}{15} \\
\hline \multicolumn{2}{|l|}{ f. Renewal of medication } & \multicolumn{2}{|l|}{54} \\
\hline \multicolumn{2}{|l|}{ g. New prescriptions } & \multicolumn{2}{|l|}{54} \\
\hline \multicolumn{2}{|l|}{ h. No actions } & \multicolumn{2}{|l|}{22} \\
\hline \multicolumn{2}{|l|}{ i. Did not understand the treatment plan } & \multicolumn{2}{|l|}{6} \\
\hline
\end{tabular}

hospital appointments and virtual clinics

\section{Discussion}

Covid-19 has caused pandemic in this century. It is important to encourage the public in general and vulnerable groups such as our study population to adopt precautionary behaviours, which is based on the correct knowledge of the epidemic and appropriate response. Many studies have examined the various levels of knowledge about infectious disease outbreaks, such as SARS, avian influenza and Covid-19 $[6,7,8,9]$ in general population, but to our knowledge there is no study addressing knowledge of covid-19 in cancer patients in developing countries.

Jordan is a middle- income country with limited resources, thus the emphasis was to limit the spread of infection and this necessitated the total lockdown and the increase of public awareness which was done through different social media [10].

In our study $83.1 \%$ believed that cancer patients are more prone to get infected with covid-19 which could be true, Case series by Liang et al. (18 cases), Zhang et al. (28 cases) and Zhang et al. (67 cases) reported a higher prevalence of cancer patients with COVID-19 infections compared with the overall population ( 1 vs $0.29 \%$ ) [4]. Nevertheless only $46.3 \%$ thought that they may become infected.

Unless people have basic knowledge about the modes of transmission, they will not respond appropriately during an outbreak [11]. In our study even though $96.5 \%$ knew that covid-19 can be 
transmitted through direct contact, only $62.7 \%$ knew that it can be transmitted through air droplets which can increase spread of infection, still $86.1 \%$ wore face masks when they get out and $85.6 \%$ wore gloves, this could be related to the instructions given through public television about protection from corona virus. The effectiveness of mask use for preventing infection, especially pandemic transmission in households, has been established [11].

Hand disinfectants significantly reduce viral counts on the hands [12], 88.1\% of participants stated that they use disinfectants. At KHCC hand disinfectants is routinely placed in all areas of the hospital to be used by patients and accompanying persons to prevent the spread of infection at the facility as we are dealing with a vulnerable group, this may have increased the awareness of the importance of hand disinfection thus the high response rate.

All participants answered that they wash their hands frequently, handwashing is a well-established means of preventing infection $[13,14]$, which is a good practice followed by the patients to reduce the risk of infection.

Many of the participants $75.1 \%$ believed that coming to the hospital increased the risk of infection. A study showed that during the pandemic almost $30 \%$ of cancer patients' infection was suspected to be hospital-associated transmission [15], 76.1\% believed that they are more prone to develop complications if they were infected, but according to published research, patients may be less prone to severe infections but are at a theoretical risk of a cytokine release syndrome that would exacerbate a COVID-19 infection [16-18].

Even though many believed that coming to the hospital may increase risk of infection with covid-19, $57.2 \%$ did not want to postpone their treatment. According to a previous study, in general, it is recommended that patients receiving curative cancer therapy should continue their treatment despite the potential risk of COVID-19 infection during anticancer therapy. Delaying treatment of metastatic disease results in deteriorated performance status, admission for symptom palliation, and progressive disease [19]. Maybe our patients were afraid that their disease will progress if they were not treated, in addition they were certain, $97 \%$ of them that the hospital is taking all measures necessary to prevent spread of infection.

The outbreak of any emerging infectious agent leads to the emergence of dynamic and uncertain situations; therefore, such emergencies need prompt and appropriate response [20]. This implies that protective health behaviour in case of emerging infectious diseases is more likely to be dependent on situational responses based on known preventive actions like social distancing [21]. For this it is quite important to study what the patients know and practice to allow for proper guidance.

Several measures were taken by KHCC to reduce risk of infection, of these all out-patients' clinics were closed to minimize contact between individuals and all surgeries were postponed for two weeks as per the recommendations of the Society of surgical oncology which assumed a delay of 3-6 months in non- 
emergency cases is acceptable based on the clinical opinion of the surgeon [22]. No appointments for surgeries were given during lockdown as answered by the survey during the clinic phone call.

Most of the participants practiced social distancing $96 \%$, this message was sent by the government as an effort to contain the disease. Even though people are not much concerned for avoiding avoid mass gatherings and adopting social distancing practices; however, when influenced by informative tools they tend to adopt it to avoid acquiring any infection[23] as was the case in our study.

Patients were under lockdown and health workers were at risk of infection, Physicians and health systems worldwide were racing to adopt virtualised treatment approaches that obviate the need for physical meetings between patients and health providers [24], thus KHCC consultants did the clinics by phone. Online medical counselling and appropriate diagnosis and treatment of critical cases to minimize patients' exposure to COVID-519 may be required during the virus outbreak as concluded by a previous study [26]. Participants were asked about their experience with the phone calls, most of the patients were called by the hospital $82.1 \%$, of them $57.7 \%$ were contacted by their primary physician and $81.1 \%$ were contacted by their clinical coordinators. Different procedures resulted from this call such as chemotherapy appointments, renewal of medications, diagnostic exams schedules and follow up appointments were given. Around $85 \%$ of patients were satisfied that they are being followed by their health care providers and $85.1 \%$ stated that all their medical problems were addressed. The findings of the 2018 US Agency for Healthcare Research and Quality's (AHRQ) telehealth systematic review found "telehealth improved outcomes or that there was no difference between telehealth and the comparators across the settings and for the clinical indications studied [26] as was the case with KHCC patients. Most of the participants knew what to do if they were infected and only a minority believed that they may not seek treatment for fear of quarantine. We did calculations between groups to study if gender, age diagnosis, level of education, residence and treatment affected knowledge and practices of oncology patients but there was no statistical significant difference between all subgroups and this could be explained by the nationwide health information provided as well as the precautionary actions and information provided by KHCC about covid- $19,63.7 \%$ of patients said that the hospital provided them with the necessary information.

\section{Conclusion}

At present, there is a global pandemic of COVID-19, In comparison with the overall population, cancer patients are at a higher risk of infection; this necessitates Cancer patients' awareness for the adoption of health care protective practices.

The present study showed that oncology patients at KHCC, which is the only comprehensive cancer hospital in Jordan, know about covid-19 and what preventive measures to follow. There was a high level of awareness between all patients regardless of other factors.

The concept of Virtual clinics is relatively new to the medical field, even though, patients were satisfied and their treatment was followed and continued based on it, such measures are highly recommended in 
these situations and can be quite successful.

\section{Declarations}

Funding: None

Conflict of interest: There was no conflict of interest

Consent: informed verbal consent was obtained prior to the interview

Availability of data and material: Available

Code availability: Not applicable.

\section{References}

1. (2020) FIP Covid-19 Information Hub - FIP - International Pharmaceutical Federation. In: Fip.org. https://www.fip.org/coronavirus.

2. (2020) Coronavirus. In: https://www.who.int/emergencies/diseases/novel-coronavirus-2019. Accessed 30 Mar 2020

3. Al-Quteimat O, Amer A (2020) The Impact of the COVID-19 Pandemic on Cancer Patients. J Clin Oncol. https://doi.org/10.1097/coc.0000000000000712 [Epub ahead of print]

4. Liang W, Guan W, Chen R et al. (2020) Cancer patients in SARS-CoV-2 infection: a nationwide analysis in China. Lancet Oncol 21:335-337. https://doi.org/10.1016/s1470-2045(20)30096-6

5. Mantwill S, Monestel-Umaña S, Schulz P (2015) The Relationship between Health Literacy and Health Disparities: A Systematic Review. PLOS ONE 10:e0145455. https://doi.org/10.1371/journal.pone.0145455

6. Wolf M, Serper M, Opsasnick L et al. (2020) Awareness, Attitudes, and Actions Related to COVID-19 Among Adults With Chronic Conditions at the Onset of the U.S. Outbreak. Ann Intern Med. https://doi.org/10.7326/m20-1239

7. Deng J, Olowokure B, Kaydos-Daniels S et al. (2006) Severe acute respiratory syndrome (SARS): Knowledge, attitudes, practices and sources of information among physicians answering a SARS fever hotline service. Public Health 120:15-19. https://doi.org/10.1016/j.puhe.2005.10.001

8. de Zwart O, Veldhuijzen I, Elam G et al. (2007) Avian Influenza Risk Perception, Europe and Asia. Emerg Infect Dis 13:290-293. https://doi.org/10.3201/eid1302.060303

9. Di Giuseppe G, Abbate R, Albano L et al. (2008) A survey of knowledge, attitudes and practices towards avian influenza in an adult population of Italy. BMC Infect Dis 8:36.

https://doi.org/10.1186/1471-2334-8-36

10. (2020) Jordan's official COVID-19 website homepage. In: http://www.corona.moh.gov.jo/. Accessed 1 Apr 2020 
11. Rubin G, Amlot R, Page L, Wessely S (2009) Public perceptions, anxiety, and behaviour change in relation to the swine flu outbreak: cross sectional telephone survey. BMJ 339:b2651-b2651. https://doi.org/10.1136/bmj.b2651

12. Larson E, Cohen B, Baxter K (2012) Analysis of alcohol-based hand sanitizer delivery systems: Efficacy of foam, gel, and wipes against influenza A (H1N1) virus on hands. Am J Infect Control 40:806-809. https://doi.org/10.1016/j.ajic.2011.10.016

13. Cowling B, Chan K, Fang V et al. (2009) Facemasks and Hand Hygiene to Prevent Influenza Transmission in Households. Ann Intern Med 151:437-446. https://doi.org/10.7326/0003-4819-1517-200910060-00142

14. Aiello A, Coulborn R, Perez V et al. (2010) A randomized intervention trial of mask use and hand hygiene to reduce seasonal influenza-like illness and influenza infections among young adults in a university setting. Int J Infect Dis 14:e320. https://doi.org/10.1016/j.ijid.2010.02.2201

15. Zhang L, Zhu F, Xie L et al. (2020) Clinical characteristics of COVID-19-infected cancer patients: a retrospective case study in three hospitals within Wuhan, China. Ann Oncol.

https://doi.org/10.1016/j.annonc.2020.03.296 [Epub ahead of print]

16. Rassy E, Assi T, Rizkallah J, Kattan J (2017) Diffuse edema suggestive of cytokine release syndrome in a metastatic lung carcinoma patient treated with pembrolizumab. Immunother 9:309-311. https://doi.org/10.2217/imt-2016-0134

17. Bersanelli M (2020) Controversies about COVID-19 and anticancer treatment with immune checkpoint inhibitors. Immunother 12:269-273. https://doi.org/10.2217/imt-2020-0067

18. Mehta P, McAuley D, Brown M et al. (2020) COVID-19: consider cytokine storm syndromes and immunosuppression. Lancet 395:1033-1034. https://doi.org/10.1016/s0140-6736(20)30628-0

19. Ueda M, Martins R, Hendrie P et al. (2020) Managing Cancer Care During the COVID-19 Pandemic: Agility and Collaboration Toward a Common Goal. J Natl Compr Canc 18:366-369. https://doi.org/10.6004/jnccn.2020.7560

20. Oliveira A, Botega L, Saran J et al. (2019) Crowdsourcing, data and information fusion and situation awareness for emergency Management of forest fires: The project DF100Fogo (FDWithoutFire). Computers, Environment and Urban Systems 77:101172. https://doi.org/10.1016/j.compenvurbsys.2017.08.006

21. Liao Q, Cowling B, Lam W et al. (2010) Situational Awareness and Health Protective Responses to Pandemic Influenza A (H1N1) in Hong Kong: A Cross-Sectional Study. PLoS ONE 5:e13350. https://doi.org/10.1371/journal.pone.0013350

22. Bartlett D, Howe J, Chang G et al. (2020) Management of Cancer Surgery Cases During the COVID-19 Pandemic: Considerations. Ann Surg Oncol 27:1717-1720. https://doi.org/10.1245/s10434-02008461-2

23. Slaughter L, Keselman A, Kushniruk A, Patel V (2005) A framework for capturing the interactions between laypersons' understanding of disease, information gathering behaviors, and actions taken during an epidemic. J Biomed Inform 38:298-313. https://doi.org/10.1016/j.jbi.2004.12.006 
24. Webster $P$ (2020) Virtual health care in the era of COVID-19. Lancet 395:1180-1181. https://doi.org/10.1016/s0140-6736(20)30818-7

25. Wang H, Zhang L (2020) Risk of COVID-19 for patients with cancer. Lancet Oncol 21:e181. https://doi.org/10.1016/s1470-2045(20)30149-2

26. Totten A, Hansen R, Wagner J et al. (2019) Telehealth for Acute and Chronic Care Consultations. https://doi.org/10.23970/ahrqepccer216 